$\begin{array}{ll}\text { Prologue de Zarathoustra } & 19\end{array}$

Les discours de Zarathoustra 35

Des trois métamorphoses $\quad 37$

Des chaires de vertu $\quad 39$

De ceux des arriere-mondes $\quad \mathbf{4 2}$

Des conlempleurs du corps $\quad 45$

Des affections de joie et de souffrance $\quad 47$

Du blême criminel $\quad 49$

Du lire et de l'écrire $\quad 52$

De l'arbre sur la montagne $\quad 54$

Des prêcheurs de mort $\quad 57$

De la guerre et des guerriers $\quad 59$

De la nouvelle idole $\quad 61$

Des mouches de la place publique $\quad 64$

De la chastelé $\quad 67$

De l'ami $\quad 69$

Des mille et une fins $\quad 71$

De l'amour du prochain $\quad 74$

De la voie du créaleur $\quad 76$

De petites jeunes et de petites vieilles $\quad 79$

De la morsure de vipère $\quad 82$

D'enfant et de mariage $\quad 84$

De la libre mort $\quad 86$

De la prodigue vertu $\quad 89$ 


\section{DEUXIĖME PARTIE}

L'enfant au miroir

Des compatissants

Des prêtres

Des verlueux

De la canaille

Des tarenlules

Des illustres sages

Le Chant de nuit

Le Chant de danse

Le Chant des tombes

De la domination de soi

Des sublimes

136

Du pays de la culture

De l'immaculée connaissance

Des érudits

De grands événements

De la rédemption

158

De la prudence avec les hommes

163

L'Heure du plus grand silence

166

\section{TROISIEME PARTIE}

Le voyageur

De la vision el de l'énigme

De la béatitude malgré soi

180

Avant que se lève le Soleil

184

De la rapetissante vertu

Sur la montagne des oliviers

De passer outre

Des renégats

De trois méchantes choses 
De la grande nostalgie 243

Le Deuxieme Chant de danse $\quad 246$

Les Sepl Sceaux (ou Le Chant du Oui el de l'Amen) $\quad 250$

\section{QUATRIÈME ET DERNIÈRE PARTIE}

Le Sacrifice du miel 257

Le Cri de détresse $\quad 261$

Dialogue avec les rois 265

La Sangsue $\quad 269$

L'Illusionniste $\quad 272$

Hors service $\quad 279$

Le Plus Hideux des hommes 284

Le Mendiant volontaire $\quad 289$

L'Ombre 293

A l'heure de midi

La Salutation $\quad 300$

La Cine $\quad 305$

De l'homme supérieur $\quad 307$

Le Chant de la mélancolie $\quad 318$

De la science $\quad 323$

Parmi les filles du désert $\quad 326$

Le Réveil 331

La Fête de l'âne 335

Le Chant du marcheur de nuit $\quad 339$

Le Signe $\quad 347$

Dates et événements de la vie de Nietzsche. 351

Les manuscrits. $\quad 358$

Notes et variantes. $\quad 361$ 
